Revista "AspaS" - № 1 - 2011 - Anais do Primeiro Seminário de Pesquisas em Andamento

uspac do Programa de Pós-Graduação em Artes Cênicas da Universidade de São Paulo.

\title{
$O$ teatro de reprise e a co-construção estética do saber. Uma reflexão da aprendizagem grupal/individual através da improvisação interativa (co-criação)
}

Rosane Rodrigues

Doutoranda em Artes Cênicas/USP

Área de Concentração: Pedagogia do Teatro

Orientador: Flávio Augusto Desgranges de Carvalho

Psicóloga, professora na formação em psicodrama do DPSedes (departamento de psicodrama do Sedes), mestre em Artes e diretora do Grupo Improvise (Teatro de Reprise). Consultório particular.

Resumo: Faço uma reflexão sobre a metodologia do Teatro de Reprise como mediador de interação e aprendizagem com o público. Defino o método e seus fundamentos baseados no psicodrama de Jacob Levy Moreno. Como o psicodrama, sua história, e a trajetória de seu criador se entrelaçam indissoluvelmente, a personalidade e biografia de Moreno são utilizadas como fio condutor na compreensão das bases do método psicodramático. Suas ideias sobre inclusão, utopia e saúde configuram um vanguardismo em sua época, noção de co-consciente e coinconsciente. Especificamente quanto ao método Teatro de Reprise, o trabalho é um estudo de como o impacto da aprendizagem grupal resultante da utilização do método em organizações, políticas públicas etc. é apreciado através de exemplos de intervenção e depoimentos de participantes.

Palavras-chave: teatro de reprise, psicodrama público, teatro espontâneo, grupo, teatro, estética

Title: The theatre of reprise and the estehetic co-construction of knowing. A reflection upon individual/group learning through the interactive improvisation (co-cretion)

Abstract: In my doctoral research I reflect on the methodology of the Playback Theatre as a mediator of interaction and learning with the audience. I define the method and its foundations based on Jacob Levy Moreno. Since the psychodrama, its history, and the path of its creator intertwine indissolubly, the personality and biography of Moreno are used as a guide in understanding the foundations of the psychodramatic method. His views on inclusion, utopia and health configure an avant-garde in his time, notion of coconscious and co-unconscious. Specifically regarding the Playback Theatre method, this work is a study on how the impact of the group learning, resulting from the use of the method in organizations, public policy and so on, is valued by some examples of intervention and testimonials from participants.

Keywords: teatro de reprise, public psychodrama, spontaneous theatre, group, theatre, esthetic

Título: El teatro de reprise y la co-construcción estética del saber. Una reflexión del aprendizaje grupal/individual a través de la improvisación interactiva (co-creación) 
Resumen: Hago una reflexión sobre la metodología del Teatro de Reprise como mediador de la interacción y aprendizaje con el público. Defino el método y sus fundamentos basados en el psicodrama de Jacob Levy Moreno. Cómo el psicodrama, su historia, y la trayectoria de su creador se entrelazan indisolublemente, la personalidad y la biografía de Moreno son utilizadas como hilo conductor en la comprensión de las bases del método psicodramático. Sus ideas sobre inclusión, utopía y salud configuran un vanguardismo en su época, así como su noción de co-consciente y co-inconsciente. Específicamente en cuánto al método de Teatro de Reprise, el trabajo es un estudio de cómo el impacto del aprendizaje grupal, resultado de la aplicación del método en organizaciones políticas, públicas, etc., se aprecia a través de ejemplos de intervención y testimonios de participantes.

Palabras-clave: teatro de reprise, psicodrama público, teatro espontáneo, grupo, teatro, estética

\section{Introdução}

Em primeiro lugar é importante que se diga que meu olhar é de uma psicóloga, mestre em artes, que trabalha há cerca de 30 anos com a abordagem psicodramática, integrando o teatro em intervenções sociais por meio do Psicodrama.

O Psicodrama é uma abordagem criada pelo romeno, radicado em Viena, Jacob L. Moreno (1889-1974) e que passou boa parte de sua vida desenvolvendo os conceitos de abordagem grupal nos Estados Unidos. Ele foi o criador da psicoterapia de grupo e de obras que inspiraram, por exemplo, Kurt Lewin a criar a teoria da Dinâmica de Grupo e Boal seu Teatro do Oprimido. Uma proposta de tratamento de toda a humanidade, batizada por Moreno de sociatria, guia sua trajetória e se alia a uma utopia de inclusão total da humanidade.

O Psicodrama é uma abordagem que permite não somente os processos psicoterápicos, como também intervenções sociais com grandes ou pequenos públicos, com objetivos de aprendizagem, culturais ou integrativos. E, por fim, mas não menos importante, o Psicodrama no Brasil criou raízes, pois a cultura brasileira e sua característica inconfundível de improvisação natural, peculiar do seu povo, facilitou sua aceitação e a consolidou. Não é por acaso que o Psicodrama teve tantos adeptos, livros 
Revista "AspaS" - № 1 - 2011 - Anais do Primeiro Seminário de Pesquisas em Andamento

uspac do Programa de Pós-Graduação em Artes Cênicas da Universidade de São Paulo.

publicados e esse expressivo número de psicodramatistas que fundaram a maior federação de psicodrama do mundo, em um só país.

\section{Teatro de Reprise como metodologia}

Em 1993, eu, juntamente com alguns colegas trouxemos a metodologia do Playback Theatre ${ }^{1}$ para o Brasil e o adaptamos para o que batizamos e ficou sendo conhecido como Teatro de Reprise. Há dez anos montei meu próprio grupo (Grupo Improvise), trabalho e dou aulas sobre esse método e também sobre formação na abordagem do psicodrama.

Ao longo dos anos de utilização da metodologia do Teatro de Reprise, percebemos, enquanto grupo, diferenças sutis ou mais expressivas a cada intervenção realizada, dependendo dos ambientes onde ela ocorre, fazendo referência não só ao espaço físico, mas também às relações sociais e políticas ali presentes. Essa metodologia é realizada em empresas privadas, públicas ou mistas, organizações de terceiro setor, congressos, workshops, escolas e espaços públicos (abertos e fechados).

A metodologia pouco clássica de se fazer psicodrama através da modalidade do Teatro de Reprise já foi questionada por psicodramatistas mais conservadores. Será que se trata de psicodrama mesmo? Aguiar (1998, p. 47) afirma que o Playback Theatre/Teatro de Reprise é uma modalidade de Teatro Espontâneo/Psicodrama. E talvez aí esteja a questão primordial levantada por Aguiar sobre o fazer psicodrama com ênfase no psico ou no drama (AGUIAR, 1998, p. 21). O Teatro de Reprise é ação sociopsicodramática, situada bem entre o teatro/arte e o psicodrama clássico, mediando um diálogo fortíssimo entre essas duas produções de sentido.

O Teatro de Reprise hoje também é um clássico que não segue nem o clássico psicodrama e nem o clássico Playback Theatre, no qual se inspirou fortemente. Enfim, como o Grupo Improvise, sob minha direção, completou dez anos de vida em 2011, 
Revista "AspaS" - № 1 - 2011 - Anais do Primeiro Seminário de Pesquisas em Andamento

IISpac do Programa de Pós-Graduação em Artes Cênicas da Universidade de São Paulo.

usando essa metodologia e tendo no grupo membros fundadores da versão brasileira do método, ${ }^{2}$ sinto-me à vontade para fazer algumas reflexões sobre o assunto.

O Teatro de Reprise é uma modalidade de intervenção sociopsicodramática (RODRIGUES, 2008), na qual em sua etapa ${ }^{3}$ de dramatização são realizadas, por meio de ego-atores, ${ }^{4}$ algumas teatralizações ${ }^{5}$ inspiradas em cenas vividas e relatadas por narradores $^{6}$ espontâneos. Portanto, é genuinamente um Teatro Espontâneo ou um Psicodrama. $^{7}$

A metodologia inspirada pelo Playback Theatre conserva alguns de seus princípios básicos e mantém os princípios fundamentais do Psicodrama, apoiando-se em conceitos como co-consciente, coinconsciente, espontaneidade, contexto dramático, realidade suplementar, entre outros (RODRIGUES, 2008). Conceitos importantes do Psicodrama, porém não implicam em entendimento destes para essa empreitada inicial sobre o assunto.

\section{Etapas do Teatro de Reprise}

Assim como no Psicodrama clássico, a primeira etapa é o aquecimento, com ou sem tema determinado. Conduzido pelo diretor, que ao contrário do teatro convencional permanece durante toda a intervenção mediando plateia e representação teatral, o aquecimento pode ter a apresentação de performances realizadas pelos ego-atores ou jogos dramáticos com a participação ampla da plateia. Alguns jogos podem ser usados, como por exemplo: Desatando e atando nós (RODRIGUES; COUTINHO, 2009), Camarim Vivo, ${ }^{8}$ Esculturas Fluidas (SALAS, 2000, p. 44) etc. O aquecimento é fundamental para firmar um contrato de coparticipação da plateia que transcende a mera colaboração. Os participantes todos devem estar num clima de co-construção voluntária e se sentindo representados quando surge um narrador espontâneo, que vai gerar a cena a ser teatralizada, seguido por outros narradores, quando há tempo.

Muitas vezes, existe um tema previamente determinado, outras vezes o tema é espontâneo, porém sempre serão aquelas pessoas presentes ao evento que ocuparão a 
prioridade do trabalho. Há então uma indução, por meio da técnica de fantasia dirigida, ${ }^{9}$ em que a plateia se concentra individualmente em suas imagens mentais, porém pretendese que o coletivo, o co-consciente e o coinconsciente adensado até aquele momento favoreçam a cada um, sua conexão grupal. Ou seja, acredita-se que as cenas produzidas pelo grupo estão legitimadas, sincronizadas e atravessadas pelas forças presentes daquela coletividade específica que se formou durante a intervenção. Obviamente, as forças culturais, mais gerais do grupo também concorrem positivamente nesse sentido, assim como na equipe profissional, que trabalha através de uma sensível escuta da plateia. A escuta, bem como o desenvolvimento técnico, é fruto de um intenso preparo prévio de sensibilidade e improvisação.

Na etapa seguinte, a direção convida e alguns participantes voluntariamente relatam suas cenas. Cada voluntário é recebido como representante da plateia na ordem em que se apresentarem. Se houver mais de um narrador a direção procede a uma eleição da plateia. Após cada relato, enquanto os ego-atores combinam a teatralização, os músicos tomam o palco e interpretam de improviso músicas que tenham relação com a cena narrada. A breve combinação dos ego-atores busca um aprofundamento simbólico e resoluções cênicas com qualidades estéticas. Os músicos possuem um papel importante no método, mantendo o aquecimento da emoção trazida pelo narrador e enriquecem a cena fazendo sons incidentais no seu transcorrer. O resultado cênico é uma reflexão tanto para o narrador (Espelho Ressonante ${ }^{10}$ ), quanto para o grupo presente, uma ressignificação do relato feito inicialmente.

A característica especial desse método em relação ao Psicodrama clássico é que o autor da cena assiste a encenação, do melhor ângulo possível da plateia. Pelo tempo que dura sua participação direta, portanto, o narrador faz parte do elenco como dramaturgo, mas não no papel ator. E, no contexto grupal, a plateia acompanha, por identificação, as reações do narrador ao que ocorre no contexto dramático, no palco.

Coerentes com os princípios psicodramáticos da socionomia, ${ }^{11}$ se levarmos as pessoas presentes - plateia e elenco - a um estado de espontaneidade, elas poderão atingir uma reflexão profunda e emocional sobre o tema, que resulte na transformação 
necessária, possível e natural a cada pessoa daquele grupo. Dessa forma, após três ou quatro cenas, baseadas em uma dramaturgia da vida real, a plateia compartilha cenas e sentimentos com os narradores. A direção então faz um apanhado das cenas contadas e resume o caminho percorrido pelo grupo por intermédio do "diálogo" entre as cenas. Em algumas intervenções pedagógicas pode-se também ao final rever o processamento do ocorrido com o grupo por algum vértice: tema, sociodinâmica etc.

Em meu exemplo, escolhi um Psicodrama Público que são intervenções psicodramáticas realizadas em eventos abertos ao público geral ou específico, em espaço aberto ou fechado que se propõe a realizar um ato e não um processo. Ou seja, que ao ser encerrado não pressupõe nenhuma continuidade direta. Aqui, poderíamos distinguir que os espaços abertos, como praças públicas, poderiam ser chamados, como denominados por Cida Davoli, de Psicodramas Líquidos, por apresentarem uma característica fragmentada de cenas descontínuas (DAVOLI, 2006, p. 84).

Já o Psicodrama Público em lugares fechados promove a possibilidade de um começo, meio e fim, mesmo que entrecortado por entradas e saídas de participantes. Em ambos os casos, há necessidade de vez por outra proceder a certa inclusão de conteúdo junto aos participantes recém chegados. O Psicodrama Público é uma intervenção social, um ato político de criação de sentidos, de diferentes e muitas verdades. Acredito que é um ambiente especial co-construído de transformação da realidade, que com a eficiência da metodologia psicodramática proporciona potência ao grupo então reunido.

Exemplo: Um relato de intervenção de Teatro de Reprise em Psicodrama Público

Para reflexão sobre Psicodramas Públicos usando a modalidade de Teatro de Reprise, apresentamos uma intervenção realizada pelo Grupo Improvise, referente a uma de suas participações no projeto dos Psicodramas Públicos no Centro Cultural São Paulo (CCSP). As intervenções no CCSP são abertas e acontecem gratuitamente todos os sábados, das 10 h30 às 13h00, contando com a direção de diferentes profissionais.

\section{Relato de uma intervenção de Teatro de Reprise em 28 de maio de 2011}


Revista "AspaS" - № 1 - 2011 - Anais do Primeiro Seminário de Pesquisas em Andamento $\underset{\text { usp }}{\text { upgac }}$ do Programa de Pós-Graduação em Artes Cênicas da Universidade de São Paulo.

Recebemos o público com a música Anunciação e Palco. O público começou com cerca de 50 pessoas e terminou com 100, pois é hábito que se mantenha aberta a possibilidade de qualquer um entrar ou sair desse evento.

Num clima de $100 \%$ inclusão, a diretora ${ }^{12}$ e autora desse texto apresentou o projeto, o Grupo Improvise e mapeou o público conforme critério de "quantas vezes já participaram do Psicodrama Público" e o quê vieram buscar. Os presentes disseram que vieram em busca de conhecimento, autoconhecimento, encontrar pessoas, matar curiosidade. Alguns não sabiam o que queriam e estavam prontos para o inusitado.

A diretora solicitou ao grupo então que caminhassem pela sala reconhecendo o espaço, se conectassem e se cumprimentassem. Enquanto caminhavam, a diretora comentou que o Grupo Improvise havia se aquecido com dois temas para este trabalho: acontecimentos mundiais desse ano e Educação e solicitou que sentissem, enquanto caminhavam, qual assunto se ligavam mais e pediu para que se agrupassem conforme o tema (um em cada lateral do palco).

Como um "toró de ideias", os grupos começaram a se aquecer com os fatos e ideias que vinham na cabeça (e são falados) em relação ao tema naquele momento e, em seguida, a diretora pediu que se reunissem em subgrupos, discutissem e definissem frases curtas (como se fosse um grito de guerra) para escrever nas cartolinas distribuídas.

Havia algumas pessoas que se posicionaram no meio, entre um tema e outro, dizendo-se indecisas, e outras que não levantaram das cadeiras. A estas ultimas, passamos uma cartolina para que cada um escrevesse uma frase, mas como continuidade da anterior de forma a compor uma história coletiva. Os que estavam indecisos decidiram-se entrando em um grupo ou compondo esta história coletiva.

Todos os grupos leram seus cartazes. Ou melhor, interpretaram os dizeres de seus cartazes como um coro ou jogral. Enquanto apresentavam, uma ego-atriz do Grupo Improvise, anotava as passagens marcantes desta grande história que o grupo contou. Ao final, interpretou teatralmente a poesia coletiva, emocionando a todos.

As frases foram: Um umbigo parafusado - quem se respeita, respeita a educação (bis); Jornal do bem: governantes decidem deixar de investir em armas e investem no 
combate a fome e educação ótima; Violência, desrespeito, descaso, corrupção, falta de merenda, Educação! Amor, tolerância, emprego, amizade...; Desenvolvimento social e Individual; Comunidade é diferente de coletivo. Coletivo para nós é ônibus. Comunidade é para nós uma casa para morar, um cachorrinho, um coração para amar; Educação não é só na escola. Professor com coragem para falar. Para saber viver junto é preciso viver só. Indicamos o filme Baraka; Jornal do bem - segunda edição: Arma Zero, fome não, natureza sem destruição; Quero viver minha vida, não interessa tragédias que a vida me impõe; Era uma vez um mundo... com vontade de ser melhor.

Após a interpretação da poesia coletiva, a diretora pediu emoções para que o grupo de ego-atores transformassem em esculturas fluidas. Foram elas: Tristeza com "um pouquinho de raiva"; Indignação "com cala-boca"; Angústia; Esperança renovada.

Em seguida, a diretora solicitou que todos fechassem os olhos e se deixassem ser atravessados por cenas da vida vivida de cada um (método Teatro de Reprise: fase da fantasia dirigida). Ao abrirem os olhos, diversos participantes queriam contar suas cenas e através de votação, o público escolheu a cena com o título: Quem olha para o que está fora não vê o que está dentro.

Uma mulher jovem foi a narradora da cena eleita. Ela foi chamada ao palco e contou que queria iniciar contextualizando o que the chamou atenção. A partir do cartaz de um dos grupos que falava da casinha, lembrou de um paciente que vem atendendo e que manifesta dificuldade de se expressar em terapia e teria lhe dito numa primeira sessão que quem o vê bem não sabe o que está por dentro dele. E que também em uma supervisão em dias seguintes a narradora tomou o papel de um paciente e entrou em contato com seu mundo subjetivo e entendeu melhor o turbilhão ao qual o seu paciente se referia. A cena que quis contar foi que no dia anterior estava em casa, estava muito frio e ela estava na "caminha, quentinha" (sic), de pijama e estava com diarreia. Mas uma turma de amigos ligou para ela ir encontrá-los. Ela ficou na dúvida, mas resolveu ir. Num barzinho se divertiu e alguns amigos debocharam dela, pois não acreditavam que ela pudesse não estar bem, pois parecia bem. Ao voltar para casa, celebrou ter voltado para o seu "quentinho". Terminou dizendo que estava lá se divertindo, mas o que estava 
acontecendo dentro dela de verdade (diarreia) ninguém sabia: Quem olha para o que esta fora não vê o que está dentro.

Diretora e narradora sentam nas cadeiras reservadas, os atores se reúnem para combinação e os músicos tocam as músicas: A Casa, Vira Virou e Roda Viva.

A cena é teatralizada numa improvisação dando ênfase na negociação interna da narradora sobre estar em casa, quentinha, protegida, mas sozinha ou sair, encontrar os amigos, ter que demonstrar que está tudo bem, mas estar acompanhada. A casa é representada por dois atores que a cada vez que ela volta lhe aconchegam sem nenhuma mudança de fisionomia. E as amigas, como um trio exageradamente alegre não oferece espaço para nenhuma dor. A cena evidencia as sensações do grupo presente de questões da educação e providências que não são tomadas por governo e nem pelas próprias pessoas. Também havia algumas situações como a mudança de sala; provocações de alguns frequentadores habituais uns com os outros e que poderiam ser encaradas como a nossa diarreia do dia. A alegria não podia ser plena.

A diretora solicitou então para que as pessoas que haviam candidatado suas cenas contassem-nas. Havia a cena de uma professora agredida por um aluno na escola; outra de um homem que sempre via outro homem espantando um cachorro até que um dia este narrador falou ao homem que espantava o cachorro que o cachorro gostava dele, que o havia escolhido e que, a partir deste dia, o homem passou a tratar o cachorro a pãode-ló (sic); um homem contou que estava no auge da sua vida profissional e sofreu uma queda na qual fraturou a perna, passando o Natal e o ano novo no hospital sozinho, pois ninguém foi vê-lo; uma estudante de psicologia, que trabalhava com educação infantil, dizia que a solução estava em trabalhar com prazer e que seríamos responsáveis pela formação dos alunos, pois a solução estaria conosco; um jovem lembrou que estava na praia e, assistindo ao vídeo da marcha da maconha, indignou-se ao ver amigos sofrendo violência pelos policiais e ajudou a agitar a passeata da liberdade de expressão, mas deparou-se com a proibição da mesma: foi proibida a passeata da liberdade de expressão ${ }^{13}$; outro Jovem contou que se lembrou de uma cena na qual presenciou uma mulher carregada de coisas e seu filho com problemas graves nas pernas. A mulher se 
angustia e o filho lhe diz: "Calma, mãe, com jeitinho tudo dá"; uma mulher recorda da participação nas manifestações das diretas já e a discussão sobre o que já foi conquistado ressoa, e, encerrando, um sociólogo compartilha que é preciso a desesperança para surgir o movimento, e fecha o trabalho com uma frase que, segundo ele, é de Florestan Fernandes, sendo bastante aplaudida: "Quando fizerem a revolução nas escolas, o povo a fará nas ruas"

Naquele dia frio, falávamos dos limites entre Coletivo e Individual. Quais são os momentos e contextos que o coletivo pode ser aconchegante? Onde e quando aparece o espaço para o individual? Não há lugar perfeito, é bom estar sozinho, mas também é bom estar junto. Quanto a pressão social nos faz estar em "Coletivo"? A dimensão de que Comunidade só existe porque algo acontece no individual.

\section{Considerações Finais}

Os psicodramas públicos do CCSP podem parecer caóticos por acolher qualquer público e por incluir todos os participantes, até mesmo alguns que "ouvem vozes internas" (audíveis apenas para seus ouvidos), que the instruem para não permitir que qualquer cena se desenvolva. Neste dia especificamente tínhamos uma assídua freqüentadora extremamente agitada e em crise psicótica, mas que participou como podia e foi incluída. Mas de fato, todos compuseram o coletivo em suas diferenças e singularidades que caracterizam o olhar psicodramático da inclusão total.

A metodologia do Teatro de Reprise, que se constitui em uma modalidade de Teatro Espontâneo adapta-se muito bem a esse projeto e por isto, pelo menos duas vezes por ano, nos apresentamos contando com um grande número de público participante. É um trabalho voluntário que dá muita alegria ao grupo fazer e é preparado com carinho, por meio de um aquecimento prévio de temas que estão nos inquietando como grupo.

No exemplo temos uma intervenção em ato, com começo meio e fim, com alguns participantes que se encontram em processo. Apesar da diversidade de lugares/contexto, há um fio condutor nas cenas narradas, um coinconsciente 
compartilhado permeando a intervenção toda, atravessada por temas do conflito entre o individual e o coletivo. O grupo desenvolveu seu percurso à sua maneira, co-construindo sua história grupal e individual na poesia coletiva. Uma história de elaboração conjunta e publicada da dor, da luta e exatamente falta de comunicação e inclusão de grupos.

Quanto à unidade funcional, direção, ego-atores e músicos, que conduziram a intervenção de Teatro de Reprise se fez necessário uma relação próxima ao público, percepção do coletivo, trabalho cênico/corporal e tolerância à fluidez e ao caos, provocados pelos fluxos aleatórios de pessoas. Quando trabalhamos num psicodrama líquido, ou seja, em espaço aberto de praça, por exemplo, tudo isto se acentua, pois a fragmentação é bem mais intensa. A tolerância e as tentativas de intimização são mais e mais necessárias tanto mais a impessoalidade se fizer presente. Agilidade, alegria e manutenção de aquecimento no pico de energia são demandadas em ambos os casos para que se produzam emoções de transformação atravessando o caos, sem buscar perfeição ou consenso. Em uma intervenção em empresa, por exemplo, a intimização é parte da organização anterior, pois a sala frequentemente é isolada, sem ruídos e os participantes entram juntos e saem juntos, exclusivizados para aquele evento.

O domínio da linguagem teatral e do psicodrama ganham grande importância nos ambientes dispersos como o da intervenção descrita. A ação estética dos ego-atores mantém a plateia concentrada na cena. Além disso, a cena ressignificada pela equipe, usando as diversas possibilidades de estéticas teatrais permite várias leituras não excludentes por parte do público, cada qual com o seu referencial de vida. O Grupo Improvise tem desenvolvido performances, principalmente em psicodramas públicos, em espaço aberto e fechado como potente disparador para o público e como síntese agregadora da equipe nos ensaios. Além disso, a utilização da música no momento da combinação mantém a conexão grupal, mantém o aquecimento das emoções. E nas cenas, ela potencializa o resultado expressivo com suas interferências.

Num psicodrama público em espaço fechado, a maneira de receber a plateia, a escolha da música tocada ou o silêncio, a interação ou não dos ego-atores, com ou sem adereços, interfere mas não determina o tema da intervenção. Mas em psicodramas 
líquidos o tema pode ser um apoio fundamental para a equipe ter foco e potência para atrair a plateia. Diferente de ambientes de grupos pré-selecionados pelo papel social ou profissional, com objetivo comum a todos, como no caso de coaching grupal contratado por uma organização ou de encontro de pais, por exemplo, onde a importância do tema proposto previamente é determinante e expressiva. Porém, por princípio, o grupo presente a qualquer intervenção de Teatro de Reprise/Espontâneo sempre pode mudar o curso total de um tema proposto, se o diretor tiver experiência e não temer desafios. Mas a liberdade na relação com o tema em um psicodrama público em espaço fechado é sem dúvida mais ampla.

Além disso, a metodologia do Teatro de Reprise enaltece, pela cena individual, o assunto coletivo. Não busca o caminho da psicoterapia, ainda que possa ser extremamente terapêutico. Em especial nas intervenções públicas, buscamos teatralizar cenas, co-criar histórias e cumprir com o nosso compromisso político de transformação da realidade social.

\section{Referências}

AGUIAR, Moyses. Teatro espontâneo e psicodrama. São Paulo: Ágora, 1998.

DAVOLI, Cida. Cenas psicodramáticas: psicodrama líquido. Revista Brasileira de Psicodrama, vol. 14, n. 1, p.79-90, 2006.

MORENO, Jacob L. Autobiografia. São Paulo: Saraiva, 1985/1997.

. Fundamentos do psicodrama. São Paulo: Summus, 1959/1983.

. O teatro da espontaneidade. São Paulo: Summus, 1923/1984.

. Psicodrama. São Paulo: Cultrix, 1946/1987.

. Psicoterapia de grupo e psicodrama. Campinas: Livro Pleno, 1969/1999.

- Quem sobreviverá? Fundamentos da sociometria, da psicoterapia de grupo e do sociodrama. Edição do estudante. São Paulo: Daimon, 1934/2008; 
Revista "AspaS" - № 1 - 2011 - Anais do Primeiro Seminário de Pesquisas em Andamento

do Programa de Pós-Graduação em Artes Cênicas da Universidade de São Paulo.

RODRIGUES, Rosane. Intervenções sociopsicodramáticas: atualização e sistematização de recursos, métodos e técnicas. In: MARRA, M.M.; FLEURY, H. J. (Org.). Grupos. Intervenção socioeducativa e método sociopsicodramático. São Paulo: Ágora, 2008, p. 101-123.

RODRIGUES, R.; COUTINHO, E. Desatando e atando nós: uma técnica para grupos. Revista Brasileira de Piscodrama, vol. 17, n. 2, 2009.

- SALAS, Jo. Playback Theatre. Uma nova forma de expressar ação e emoção. São Paulo: Ágora, 2000.

1 Técnica derivada do psicodrama criada por Jonathan Fox, em 1975 (SALAS, 2000).

2 Neste ano, foi fundado o Grupo Reprise, que desenvolveu o modo brasileiro de fazer o Playback Theatre, desfeito em 2000. Três dos integrantes fundadores, Rosane Rodrigues, Eduardo Coutinho e Alexandre Aguiar, criador da parte musical do Teatro de Reprise, criaram o Grupo Improvise.

3 No psicodrama clássico utilizam-se três etapas: aquecimento, dramatização e sharing

4 Ego-ator: em psicodrama clássico, usa-se o termo ego-auxiliar para designar quem entra em cena junto com o protagonista. Quando se trabalha com narradores e não protagonistas, os atores são treinados para, a partir de sua sensibilidade, encenarem a vida do narrador sem que esse entre em cena, e foram chamados por Moreno de ego-atores.

5 Rodrigues faz uma distinção entre dramatizar e teatralizar já publicada (2008). Resumindo, teatralizar em psicodrama é ir para a cena com roteiro prévio, sendo que ao dramatizar, o roteiro vai sendo construído a cada instante. Ambos são improvisados, porém são estratégias de co-construção diferentes.

6 Narrador: emergente grupal que relata sua cena recordada, vivida ou sonhada dormindo, e a assiste encenada por ego-atores que a ressignificam, fundados no coinconsciente grupal e na mediação da direção.

7 Psicodrama aqui é usado como denominação genérica, portanto como sinônimo de Teatro Espontâneo.

8 Técnica criada por Rosane Rodrigues que usa os ego-atores para serem modelados por grupos de voluntários no gestual e figurino, com personagens do cotidiano da plateia. E, após a criação coletiva, os atores se comportam de acordo com as instruções precisas dos grupos.

9 Também um conceito já definido por Rodrigues e já publicado (idem).

10 Espelho Ressonante: ao relatar sua cena vivida, o narrador assiste à ressonância de seu relato em egoatores. A ressonância poderá vir em forma de cena representada, em forma simbólica ou em esculturas fluidas, conforme orientação da direção na modalidade adotada.

11 Socionomia: nome dado a teoria de Moreno do estudo das leis sociais: a sociometria, a sociodinâmica e a sociatria (MORENO, 1999, p. 33)

12 E membro da equipe que organiza voluntariamente o projeto dos Psicodramas Públicos do CCSP.

13 A passeata ocorreu no final de semana anterior. Só foi liberada se não fosse a passeata da maconha, e sim a da liberdade de expressão, mas os participantes não deveriam dizer a palavra maconha. Como "disseram", a multidão foi coibida com muita violência por parte da polícia. 